\title{
Papers
}

\section{Risk for schizophrenia and schizophrenia-like psychosis among patients with epilepsy: population based cohort study}

Ping Qin, Huilan Xu, Thomas Munk Laursen, Mogens Vestergaard, Preben Bo Mortensen

\begin{abstract}
Objectives To investigate whether age at onset of epilepsy, type of epilepsy, family history of psychosis, or family history of epilepsy affect the risk of schizophrenia or schizophrenia-like psychosis among patients with epilepsy.

Design Comparison of population based data.

Setting Danish longitudinal registers.

Subjects The cohort comprised 2.27 million people.

Main outcome measures Epilepsy, psychosis, personal birth data.

Results We found an increased risk of schizophrenia (relative risk $2.48,95 \%$ confidence interval 2.20 to 2.80 ) and schizophrenia-like psychosis $(2.93,2.69$ to 3.20$)$ in people with a history of epilepsy. The effect of epilepsy was the same in men and in women and increased with age. Family history of psychosis and a family history of epilepsy were significant risk factors for schizophrenia and schizophrenia-like psychosis, and the effect of epilepsy, both in cases and families, was greater among people with no family history of psychosis. In addition, the increased risk for schizophrenia or schizophrenia-like psychosis did not differ by type of epilepsy but increased with increasing number of admissions to hospital and, particularly, was significantly greater for people first admitted for epilepsy at later ages.

Conclusions There is a strong association between epilepsy and schizophrenia or schizophrenia-like psychosis. The two conditions may share common genetic or environmental causes.
\end{abstract}

\section{Introduction}

The association between epilepsy and psychosis has been researched since the nineteenth century. Several studies ${ }^{1-4}$ but not all $^{56}$ have found a higher prevalence of schizophrenia-like psychosis in patients with epilepsy compared with the general population. Yet many questions remain unanswered and large scale studies using empirical data are scant. ${ }^{7}$ The causal mechanism underlying the association is unclear. Seizures may damage the brain, which may in turn increase the risk of schizophrenialike psychosis, or the two conditions may share common aetiological factors. These hypotheses may be disentangled by evaluating the risk of schizophrenia-like psychosis in people with a family history of epilepsy. ${ }^{8}$ Genetic vulnerability to psychosis may facilitate the development of psychosis in the patients with epilepsy. ${ }^{90}$ However, there have been no published family history studies with appropriate methods. ${ }^{8}$ In addition, differences in risk of developing psychosis-for example, by type of epilepsy, age at onset, and number of admission to hospitalremain poorly understood.

In this population based cohort study we examined the risk of schizophrenia or schizophrenia-like psychosis associated with a history of epilepsy using data from Danish longitudinal registers. We also investigated how and to what extent this risk is influenced by family histories of psychosis and of epilepsy.

\section{Methods}

Subjects and data assessment

All data in this study were retrieved from Danish longitudinal registers and merged by means of the unique personal identification number, given to all Danes at birth and to new residents in Denmark. ${ }^{11}$ The number for each individual is stored in the Danish civil registration system together with information on vital status, emigration, address, and the identification numbers of mother, father, and siblings. It is used in all national registers, thus enabling accurate linkage of information across registers at the individual level.

We identified virtually all of 2315857 people who were born in Denmark from 1 January 1950 to 31 December 1987 and could be linked to their mother. We excluded individuals who were not alive at the 15 th birthday, who died or emigrated before the year 1977, and who had been admitted to a psychiatric hospital before the onset of epilepsy or who had been admitted with a schizophrenia-like psychosis before the age of 15 (total number 45475 ). We restricted recruitment to those born in 1950 and afterwards with an identified mother because we wanted to examine the effect of family history and people born after 1950 more often had registered links to parents. We chose to follow people who were alive at the 15th birthday because schizophrenia-like psychosis is rare among people under 15 years old. We excluded people with a psychiatric history before admission for epilepsy because we focused on history of epilepsy as an exposure. We thus included 2270372 people and followed this cohort from their 15th birthday or 1 January 1977 (whichever came later) until the date of onset of schizophrenia or schizophrenia-like psychosis, the date of death, the date of emigration, or 31 December 2002 (whichever came first).

Treatment in Danish hospitals is free for all residents. Individual data on every admission to general hospitals have been recorded in the national hospital register ${ }^{12}$ since 1977, and to psychiatric hospitals in the Danish psychiatric central register $^{13}$ since 1967. Data on outpatient contacts (visits to emergency department, hospital clinics, or calls for ambulance) became available in the registers after 1995. Diagnoses of illness in these registers were coded according to ICD-8 (international 
classification of diseases, eighth revision) until the end of 1993 and ICD-10 (10th revision) afterwards.

We retrieved personal data on epilepsy (ICD-8 code 345; ICD-10 code G40) from 1 January 1977 to 31 December 2002 from the Danish national hospital register. ${ }^{12}$ Examination of inpatient and outpatient data from 1995 to 2002 showed that the annual incidence of epilepsy was about 65 per 100000 population, and in about $80 \%$ of all incident cases the patient was admitted to hospital for treatment. Because of this and because these data have been available since 1977 we considered only inpatients. We categorised epilepsy into four types according to the diagnosis at each admission: complex partial seizures (ICD-8 code 345.31; ICD-10 code G40.2), other partial seizures (ICD-8 codes 345.30, 345.38, 345.39; ICD-10 code G40.0, G40.1), generalised epilepsy (ICD-8 codes 345.09, 345.10, 345.11; ICD-10 code G40.3), and other or unspecified epilepsy (ICD-8 codes 345.18, 345.19, 345.29, 345.99; ICD-10 codes G40.4, G40.5, G40.6, G40.7, G40.8, G40.9, G41). We grouped the age at onset (first record in the register) into eight categories-that is, 0-4, 5-9, $10-14,15-19,20-24,25-29,30-34$, or $\geq 35$ years. We also constructed a variable indicating the total number of hospital admissions for epilepsy until the onset of schizophrenia or schizophrenia-like psychosis.

We obtained psychiatric information from the Danish psychiatric central register. ${ }^{13}$ Our diagnoses of interest were schizophrenia (ICD-8 code 295; ICD-10 code F20) and the broad category of schizophrenia-like psychosis (ICD-8 codes 295, 297, 298.39, 301.83; ICD-10 codes F20, F21, F23, F24, F25, F28, F29). The date of onset referred to the date of first admission to a psychiatric hospital because of schizophrenia or schizophrenia-like psychosis that was recorded on the register.

To get data on family history of psychosis and epilepsy, we used the civil registration system to identify fathers, siblings, and mothers of study subjects and then linked the identification numbers of parents and siblings to the psychiatric central register and the national hospital register. Of all cohort members for whom we could identify a mother, $97.3 \%$ also had registered links to a father and $84.5 \%$ had links to at least one sibling. We defined psychosis in family members hierarchically: schizophrenia (ICD-8 code 295; ICD-10 code F20), schizophrenia-like psychosis (ICD-8 codes 297, 298.39, 301.83; ICD-10 codes F21, F23, F24, F25, F28, F29), or affective psychosis (ICD-8 codes 296.09, 296.19, 296.29, 296.89, 296.99, 298.09, 298.19, 300.19, 300.49; ICD-10 codes F30-F39). A family history of psychosis or epilepsy means that at least one parent or sibling had been admitted to hospital for psychosis or epilepsy before the index case was admitted for schizophrenia or schizophrenia-like psychosis.

\section{Statistical analysis}

We assessed the relative risk of schizophrenia or schizophrenialike psychosis through log-linear Poisson regression with the GENMOD procedure, using SAS software, version 8 (SAS Institute, Cary, NC). $\mathrm{P}$ values were based on two tailed likelihood ratio tests, and 95\% confidence intervals were calculated by Wald's test. Interactions between variables and linear trend were examined by means of the likelihood ratio test.

We controlled for possible confounding by adjusting data for age, sex, calendar year of diagnosed psychosis (1977-81, 1982-7, 1988-93, 1994-9), maternal and paternal age at birth, birth order, and place of birth (capital, suburb of capital, city with more than 100000 inhabitants, town with more than 10000 inhabitants, and rural area). We treated age, calendar year of diagnosis, epilepsy status, type of epilepsy, and schizophrenia or schizophrenia-like psychosis status as well as the family historical data as time dependent variables.

\section{Results}

In our cohort of 2.27 million people, 34494 (1.5\%) had a history of epilepsy, with a median age of 14.7 at the first admission. During follow-up, $276(0.8 \%)$ of them were later admitted to hospital for schizophrenia and 519 (1.5\%) for schizophrenia-like psychosis. The median duration between the first admission for epilepsy and the first admission of schizophrenia or of schizophrenia-like psychosis was 8.2 years or 8.0 years, respectively. Table 1 displays the distribution of cases and person years at risk in our cohort.

\section{Main effect of epilepsy}

A history of epilepsy was associated with an increased risk of schizophrenia or schizophrenia-like psychosis; and the effect remained virtually unchanged when we controlled for various potential confounders (table 2). People with epilepsy had 2.48 times the risk of schizophrenia (95\% confidence interval 2.20 to 2.80) and 2.93 times the risk of schizophrenia-like psychosis (2.69 to 3.20) compared with the general population.

The impact of epilepsy on the risk of schizophrenia or schizophrenia-like psychosis was not statistically different by sex (test of sex interaction: $\mathrm{P}=0.31$ for schizophrenia, $\mathrm{P}=0.51$ for schizophrenia-like psychosis) but differed significantly by age $(\mathrm{P}<0.01$ for schizophrenia, $\mathrm{P}=0.04$ for schizophrenia-like psychosis). Stratified analyses by age showed that the relative risk of schizophrenia was 2.03 (1.67 to 2.47), 2.28 (1.88 to 2.78), and 4.00 (3.14 to 5.09) for people aged 15-24, 25-34, and $\geq 35$, respectively. The corresponding relative risks for schizophrenialike psychosis were 2.38 (2.07 to 2.74 ), 3.13 (2.73 to 3.58 ), and 3.77 (3.08 to 4.61$)$.

These results were virtually unchanged when we excluded people who were registered with epilepsy for the first time between 1977 and 1982, although some of these people could be prevalent cases with onset of epilepsy before January 1977 (data not shown).

\section{Family history of psychosis and epilepsy}

A family history of psychosis and a family history of epilepsy were significant risk factors for schizophrenia and schizophrenia-like psychosis after we adjusted for personal history of epilepsy (table 2). A family history of schizophrenia increased the risk of schizophrenia by a factor of 7.57 (6.98 to 8.20) and the risk of schizophrenia-like psychosis by a factor of 6.24 (5.83 to 6.69), while the figures for family history of epilepsy were 1.11 (1.01 to 1.22) for schizophrenia and 1.20 (1.11 to 1.29) for schizophrenia-like psychosis.

Moreover, our data indicate that the effect of both personal and familial history of epilepsy interacted with the effect of a family history of psychosis (test of interaction: $\mathrm{P}=0.0081$ and $\mathrm{P}=0.0732$, respectively, for schizophrenia-like psychosis). Table 3 shows that a personal history of epilepsy had a stronger effect on the risk for schizophrenia or schizophrenia-like psychosis in people without a family history of psychosis than for people with it. At the same time, a family history of epilepsy significantly increased the risk only for people with no family history of psychosis.

\section{Type of epilepsy, age at admission, and number of admissions}

All types of epilepsy significantly increased the risk of developing schizophrenia or schizophrenia-like psychosis (table 4). The rela- 
Table 1 Distribution of cases with schizophrenia and schizophrenia-like psychosis and person years at risk in the study cohort of 2.27 million people

\begin{tabular}{|c|c|c|c|c|}
\hline \multirow[b]{2}{*}{ Variables } & \multicolumn{2}{|c|}{ Schizophrenia } & \multicolumn{2}{|c|}{ Schizophrenia-like psychoses } \\
\hline & Cases & Person years & Cases & Person years \\
\hline \multicolumn{5}{|l|}{ Sex: } \\
\hline Men & 7072 & 20200340 & 10627 & 20156078 \\
\hline Women & 3759 & 17709673 & 7316 & 17666892 \\
\hline \multicolumn{5}{|l|}{ Age (years): } \\
\hline $15-19$ & 1297 & 8722003 & 2622 & 8718397 \\
\hline $20-24$ & 3292 & 8770558 & 5228 & 8758915 \\
\hline $25-29$ & 2725 & 7653813 & 4409 & 7635826 \\
\hline $30-34$ & 1766 & 5869142 & 2967 & 5848858 \\
\hline $35-39$ & 1106 & 4002281 & 1765 & 3984623 \\
\hline $40-44$ & 509 & 2167083 & 769 & 2155659 \\
\hline$\geq 45$ & 136 & 725134 & 183 & 720691 \\
\hline \multicolumn{5}{|l|}{ History of epilepsy : } \\
\hline No & 10555 & 37532200 & 17424 & 37448638 \\
\hline Yes & 276 & 377813 & 519 & 374332 \\
\hline \multicolumn{5}{|l|}{ Type of epilepsy: } \\
\hline Complex partial epilepsy & 26 & 32057 & 50 & 31543 \\
\hline Other partial epilepsy & 9 & 14978 & 21 & 14881 \\
\hline Generalised epilepsy & 61 & 97314 & 133 & 96239 \\
\hline Other or unspecified & 180 & 233678 & 315 & 231881 \\
\hline \multicolumn{5}{|l|}{ Age (years) at first admission: } \\
\hline $0-4$ & 19 & 38720 & 27 & 38679 \\
\hline $5-9$ & 30 & 61813 & 61 & 61525 \\
\hline $10-14$ & 46 & 80089 & 88 & 79656 \\
\hline 15-19 & 53 & 74760 & 103 & 74069 \\
\hline $20-24$ & 50 & 57498 & 105 & 56779 \\
\hline $25-29$ & 44 & 35648 & 75 & 35019 \\
\hline $30-34$ & 20 & 17511 & 38 & 17026 \\
\hline$\geq 35$ & 14 & 11989 & 22 & 11790 \\
\hline \multicolumn{5}{|l|}{ No of hospital admissions: } \\
\hline 1 & 147 & 220799 & 260 & 219161 \\
\hline 2 & 52 & 72337 & 94 & 71742 \\
\hline 3 & 28 & 32649 & 56 & 32347 \\
\hline$\geq 4$ & 49 & 52242 & 109 & 51294 \\
\hline \multicolumn{5}{|l|}{ Family history of psychosis: } \\
\hline No & 8852 & 35689583 & 14897 & 35618931 \\
\hline Schizophrenia & 646 & 308909 & 863 & 304996 \\
\hline Schizophrenia-like psychoses & 459 & 399331 & 709 & 395556 \\
\hline Affective psychoses & 874 & 1512190 & 1474 & 1503487 \\
\hline \multicolumn{5}{|l|}{ Family history of epilepsy: } \\
\hline No & 10405 & 36733117 & 17205 & 36650212 \\
\hline Yes & 426 & 1176896 & 738 & 1172757 \\
\hline
\end{tabular}

tive risk associated with complex partial epilepsy was slightly higher than the others, but the differences were not significant.
The effect of epilepsy differed significantly according to age at first admission for epilepsy and number of admissions. The

Table 2 Relative risk (95\% confidence interval) of schizophrenia and schizophrenia-like psychosis associated with epilepsy and family history of psychosis and epilepsy

\begin{tabular}{|c|c|c|c|c|}
\hline \multirow[b]{2}{*}{ Variable } & \multicolumn{2}{|c|}{ Schizophrenia } & \multicolumn{2}{|c|}{ Schizophrenia-like psychoses } \\
\hline & Crude & Adjusted $^{*}$ & Crude & Adjusted $^{\star}$ \\
\hline \multicolumn{5}{|l|}{ Personal history of epilepsy: } \\
\hline No (reference) & 1 & 1 & 1 & 1 \\
\hline Yes & 2.60 (2.31 to 2.93$) \dagger$ & $2.48(2.20$ to 2.80$) \dagger$ & 2.98 (2.73 to 3.25$) \dagger$ & 2.93 (2.69 to 3.20$) \dagger$ \\
\hline \multicolumn{5}{|l|}{ Family history of psychosis: } \\
\hline № (reference) & 1 & 1 & 1 & 1 \\
\hline Schizophrenia & $8.43(7.78$ to 9.13$) \dagger$ & $7.57(6.98$ to 8.20$) \dagger$ & $6.77(6.32$ to 7.25$) \dagger$ & 6.24 (5.83 to 6.69$) \dagger$ \\
\hline Schizophrenia-like psychosis & $4.63(4.22$ to 5.09$) \dagger$ & 4.28 (3.89 to 4.70$) \dagger$ & 4.29 (3.97 to 4.62$) \dagger$ & 4.03 (3.73 to 4.35$) \dagger$ \\
\hline Affective psychosis & $2.33(2.17$ to 2.50$) \dagger$ & $2.25(2.10$ to 2.42$) \dagger$ & $2.34(2.22$ to 2.47$) \dagger$ & $2.27(2.15$ to 2.40$) \dagger$ \\
\hline \multicolumn{5}{|l|}{ Family history of epilepsy: } \\
\hline № (reference) & 1 & 1 & 1 & 1 \\
\hline Yes & $1.28(1.16$ to 1.41$) \dagger$ & 1.11 (1.01 to 1.22$) \ddagger$ & $1.34(1.25$ to 1.44$) \dagger$ & $1.20(1.11$ to 1.29$) \dagger$ \\
\hline
\end{tabular}


Table 3 Adjusted relative risks ${ }^{\star}$ (95\% confidence intervals) associated with epilepsy in cases and family relatives, stratified analysis according to family history of psychosis $\dagger$

\begin{tabular}{|c|c|c|}
\hline Epilepsy & Schizophrenia & Schizophrenia-like psychosis \\
\hline \multicolumn{3}{|l|}{ No family history of psychosis } \\
\hline Personal history of epilepsy & 2.61 (2.29 to 2.99$) \ddagger$ & $3.12(2.83$ to 3.43$) \ddagger$ \\
\hline Family history of epilepsy & $1.17(1.05$ to 1.31$) \ddagger$ & 1.26 (1.15 to 1.37$) \ddagger$ \\
\hline \multicolumn{3}{|c|}{ Family history of schizophrenia } \\
\hline Personal history of epilepsy & 2.60 (1.78 to 3.80$) \ddagger$ & 2.72 (2.04 to 3.63$) \ddagger$ \\
\hline Family history of epilepsy & 0.96 (0.72 to 1.29$)$ & 1.10 (0.89 to 1.37$)$ \\
\hline \multicolumn{3}{|c|}{ Family history of schizophrenia-like psychosis } \\
\hline Personal history of epilepsy & 1.50 (0.77 to 2.91$)$ & 1.91 (1.18 to 3.09$) \ddagger$ \\
\hline Family history of epilepsy & 1.08 (0.76 to 1.54$)$ & 1.11 (0.84 to 1.48$)$ \\
\hline \multicolumn{3}{|c|}{ Family history of affective psychosis } \\
\hline Personal history of epilepsy & $1.79(1.11$ to 2.91$) \ddagger$ & $1.81(1.18$ to 2.77$) \ddagger$ \\
\hline Family history of epilepsy & $0.91(0.65$ to 1.26$)$ & 0.96 (0.72 to 1.27$)$ \\
\hline \multicolumn{3}{|c|}{$\begin{array}{l}\text { *Adjusted for age, sex, calendar year of diagnosis, place of birth, paternal and maternal age at } \\
\text { birth, and birth order. Test of interaction-personal history of epilepsy and family history of } \\
\text { psychosis: } P=0.14 \text { for schizophrenia, } P<0.01 \text { for schizophrenia-like psychosis; family history of } \\
\text { epilepsy and family history of psychosis: } P=0.18 \text { for schizophrenia, } P=0.07 \text { for } \\
\text { schizophrenia-like psychosis. } \\
+ \text { References were no epilepsy in cases and no family history of epilepsy. } \\
\ddagger P<0.01 \text {. }\end{array}$} \\
\hline
\end{tabular}

relative risk increased consistently with increasing age at onset (table 5). For every five year increase in age at diagnosis the increase was linear, resulting in an analogous relative risk of 1.20 (1.12 to $1.28, \mathrm{P}<0.0001)$ for schizophrenia of 1.20 (1.14 to 1.26 , $\mathrm{P}<0.0001)$ for schizophrenia-like psychosis. This effect was also evident when we stratified analyses by age. The relative risk for schizophrenia or schizophrenia-like psychosis also tended to be higher for people with multiple admissions for epilepsy.

\section{Discussion}

This large population study shows that people with a history of epilepsy have nearly 2.5 times the risk of developing schizophrenia and nearly three times the risk of developing a schizophrenia-like psychosis compared with the general population. The risk is same for men and women but increases with age. It also indicates that both a family history of psychosis and a family history of epilepsy increase the risk for schizophrenia or schizophrenia-like psychosis in the general population. The effect of epilepsy, both in cases and in families, is modified by the effect of a family history of psychosis; the increase in risk is more pronounced for people with no family history of psychosis. The increased risk associated with epilepsy is similar in patients with various types of epilepsy, but it increases with increasing number of hospital admissions for epilepsy, and, in particular, it was significantly greater with increasing age of first for people who had their first admission for epilepsy.

\section{Strengths and weaknesses}

The possibility of linking personal information from various Danish longitudinal registers allowed us to follow a large population based cohort for a long period. This yields high statistical power and enables the assessment of interactions between

Table 4 Relative risks* for schizophrenia and like psychosis according to type of epilepsy

\begin{tabular}{|c|c|c|c|c|}
\hline \multirow[b]{2}{*}{ Type of epilepsy† } & \multicolumn{2}{|c|}{ Schizophrenia } & \multicolumn{2}{|c|}{ Schizophrenia-like psychosis } \\
\hline & Crude & Adjusted $\ddagger$ & Crude & Adjusted‡ \\
\hline None (reference) & 1 & 1 & 1 & 1 \\
\hline Complex partial epilepsy & 2.88 (1.96 to 4.24$)$ & 2.80 (1.90 to 4.11$)$ & 3.41 (2.58 to 4.50$)$ & 3.38 (2.56 to 4.46$)$ \\
\hline Other partial epilepsy & 2.14 (1.11 to 4.11$)$ & 2.18 (1.13 to 4.19$)$ & 3.03 (1.98 to 4.65$)$ & 3.18 (2.07 to 4.88$)$ \\
\hline Generalised epilepsy & 2.23 (1.73 to 2.87 ) & 2.08 (1.62 to 2.68$)$ & 2.97 (2.50 to 3.52$)$ & 2.81 (2.37 to 3.33 ) \\
\hline Other or unspecified epilepsy & 2.74 (2.36 to 3.17$)$ & 2.63 (2.27 to 3.05$)$ & 2.92 (2.61 to 3.26$)$ & 2.91 (2.60 to 3.24 ) \\
\hline
\end{tabular}

${ }^{*}$ All significant at $\mathrm{P}<0.01$.

TTest of effect differences by type of epilepsy: $P=0.14$ for schizophrenia and $P=0.26$ for schizophrenia-like psychosis.

$\ddagger$ Adjusted for sex, age, calendar year of diagnosis, paternal and maternal age at birth, birth order, and family histories of epilepsy and of psychosis as well as age at onset of epilepsy and total number of admissions.

Table 5 Relative risks (95\% confidence intervals) of schizophrenia or schizophrenia-like psychosis in relation to age at first admission and total number of admissions for epilepsy

\begin{tabular}{|c|c|c|c|c|}
\hline \multirow[b]{2}{*}{ Epilepsy history } & \multicolumn{2}{|c|}{ Schizophrenia } & \multicolumn{2}{|c|}{ Schizophrenia-like psychosis } \\
\hline & Crude & Adjusted $^{*}$ & Crude & Adjusted* \\
\hline \multicolumn{5}{|c|}{ Age (years) at first admissiont: } \\
\hline No epilepsy (reference) & 1 & 1 & 1 & 1 \\
\hline $0-4$ & 1.74 (1.11 to 2.74$) \ddagger$ & 1.77 (1.11 to 2.84 & $1.50(1.03$ to 2.19 & 1.47 (1.00 to 2.17$) \S$ \\
\hline $5-9$ & 1.73 (1.21 to 2.47$) \ddagger$ & 1.56 (1.07 to 2.29 & $2.13(1.66$ to 2.74$) \ddagger$ & 1.86 (1.42 to 2.44$) \ddagger$ \\
\hline $10-14$ & 2.04 (1.53 to 2.73$) \ddagger$ & 1.83 (1.33 to 2.51 & 2.37 (1.93 to 2.93)‡ & 1.96 (1.56 to 2.48$) \ddagger$ \\
\hline 15-19 & 2.52 (1.92 to 3.30)‡ & $2.33(1.71$ to 3.19 & 2.99 (2.46 to 3.63)‡ & 2.43 (1.94 to 3.06$) \ddagger$ \\
\hline $20-24$ & 3.09 (2.34 to 4.08$) \ddagger$ & 2.77 (2.02 to 3.80$) \ddagger$ & 3.97 (3.28 to 4.82) & 3.14 (2.50 to 3.93$)$ \\
\hline $25-29$ & 4.39 (3.26 to 5.90$) \ddagger$ & 4.17 (3.00 to 5.79) $\ddagger$ & 4.60 (3.67 to 5.77) & 3.95 (3.07 to 5.08$) \ddagger$ \\
\hline $30-34$ & 4.06 (2.62 to 6.30$) \ddagger$ & 3.92 (2.48 to 6.19$) \ddagger$ & 4.80 (3.49 to 6.59)‡ & 4.37 (3.13 to 6.10$) \ddagger$ \\
\hline$\geq 35$ & 4.15 (2.46 to 7.01$) \ddagger$ & 4.51 (2.63 to 7.72$) \ddagger$ & 4.01 (2.64 to 6.09)‡ & 4.52 (2.94 to 6.94$) \ddagger$ \\
\hline \multicolumn{5}{|l|}{ No of admissionsf: } \\
\hline 1 (reference) & 1 & 1 & 1 & 1 \\
\hline 2 & 1.08 (0.79 to 1.48$)$ & $1.17(0.85$ to 1.60$)$ & 1.10 (0.87 to 1.40$)$ & 1.17 (0.92 to 1.48$)$ \\
\hline 3 & 1.29 (0.86 to 1.93$)$ & 1.41 (0.94 to 2.12) & $1.46(1.09$ to 1.95$) \ddagger$ & 1.57 (1.17 to 2.09$) \neq$ \\
\hline$\geq 4$ & 1.41 (1.02 to 1.95)§ & 1.48 (1.07 to 2.05$) \S$ & $1.79(1.43$ to 2.24$) \ddagger$ & 1.88 (1.50 to 2.35$) \ddagger$ \\
\hline
\end{tabular}

${ }^{*}$ Adjusted for sex, age, calendar year of diagnosis, paternal and maternal age at birth, birth order and family histories of epilepsy and of psychosis, type of epilepsy as well as all variables shown in the table.

†Trend test: analogous relative risk was 1.20 (1.12 to $1.28, \mathrm{P}<0.001)$ for schizophrenia, and $1.20(1.14$ to $1.26, \mathrm{P}<0.001)$ for schizophrenia-like psychosis.

$\ddagger \mathrm{P}<0.01$.

$\S \mathrm{P}<0.05$.

१Applies only to people with history of admission for epilepsy. 
variables. The data in these registers are collected systematically and independently of any specific research, which may reduce the risk of differential misclassification bias. Our study was limited because we included only inpatients into the analyses as records on outpatients were not available in the registers (until 1995). Thus we may have selected more severely ill patients, and such selection might bias our estimations. We believe, however, this bias is limited because the annual incidence of registered epilepsy of 65 per 100000 population in Denmark is comparable with that found in, for example, the US, ${ }^{14}$ and in nearly $80 \%$ of all incident cases patients are admitted for hospital treatment in Denmark. Also, as the Danish health system is public and free our study is probably not subject to selection bias due to socioeconomic differences in access to care.

\section{Comparison with other studies}

To our knowledge this is the first population based study on epilepsy and schizophrenia-like psychosis that has taken the family history of psychosis and epilepsy into consideration and examined the interactions between these factors. Our results, on a general population level, corroborate results of previous clinical studies, ${ }^{3}$ suggesting a strong association between epilepsy and schizophrenia-like psychosis. Also, our findings of a high risk of schizophrenia or schizophrenia-like psychosis associated with a family history of psychosis are in line with the literature reporting aggregation of psychoses in families due to shared genetic or environmental factors, or both. ${ }^{15-18}$ We think that this study is the first to show that a family history of epilepsy increases the risk of schizophrenia or schizophrenia-like psychosis even after adjustment for the effects of personal history of epilepsy and other factors. This finding suggests that genetic or environmental factors shared by family members may have an important role. Moreover, our findings that both personal and familial history of epilepsy interact with the family history of psychosis, and that the effect of epilepsy is largely modified by the effect of a family history of psychosis, underlie the suggestion that the two conditions-that is, epilepsy and schizophrenia or schizophrenialike psychosis-may share common genetic or environmental causes, or both.

With regard to the type of epilepsy, a few studies have reported that people with temporal lobe epilepsy are significantly susceptible to psychosis. ${ }^{410} 19$ We also noted a slightly stronger effect with complex partial epilepsy (temporal lobe epilepsy) than, for example, generalised epilepsy, and risk for schizophrenia-like psychosis, but the differences were not significant.

Reports are inconsistent on the role of age at onset of epilepsy in the risk for schizophrenia-like psychosis. Some studies have shown no difference in age at onset of epilepsy, ${ }^{20}{ }^{21}$ some have reported an earlier age at onset in patients with psychosis, ${ }^{22}{ }^{23}$ and others have shown a later age at onset. ${ }^{24}$ These studies, however, were based on small clinical samples with large variations in the inclusion criteria for participants as well as in the measurement of psychosis. In our study we followed a large cohort for a long period and found that the relative risk of schizophrenia or schizophrenia-like psychosis was significantly greater the older people were when they were first admitted for epilepsy.

Evidence from experiments has suggested that deficits in behaviour and cognition caused by seizures probably depend on the age at which seizures occur (less severe deficits at younger ages) and frequency and severity of seizures, and may not become obvious until long after the onset of the epilepsy. ${ }^{25}$ These theories seem to explain our findings regarding the greater risk

\section{What is already known on this topic}

Several studies, but not all, have found a higher prevalence of schizophrenia-like psychosis in patients with epilepsy compared with the general population

\section{What this study adds}

People with a history of epilepsy are at increased risk for schizophrenia and schizophrenia-like psychosis

Both a family history of epilepsy and a family history of psychosis are significant risk factors for schizophrenia and schizophrenia-like psychosis

The increased risk associated with both personal and familial history of epilepsy is stronger among people with no family history of psychosis

The increased risk for schizophrenia or schizophrenia-like psychosis does not differ by type of epilepsy, but it increases with increasing number of admissions to hospital and particularly with increasing age at the first admission for epilepsy

associated with, for example, increasing age, age at onset of epilepsy, and number of admission for epilepsy.

Contributors: All authors participated in discussions about study design, analysis, and interpretation of the data and contributed to revision of the manuscript. PQ, HX, and TML analysed the data. HX prepared the first draft of manuscript. PQ wrote the report, finalised the manuscript, and is guarantor.

Funding: Stanley Medical Research Institute, USA, and the Danish Medical Research Council (grant No 22-02-0207). The National Centre for Register-based Research is supported by Danish National Research Foundation, Denmark.

Competing interests: None declared.

Ethical approval: Danish Data Protection Agency.

Bredkjaer SR, Mortensen PB, Parnas J. Epilepsy and non-organic non-affective psychosis. National epidemiologic study. Br J Psychiatry 1998;172:235-8.

Jalava M, Sillanpaa M. Concurrent illnesses in adults with childhood-onset epilepsy: a population-based 35-year follow-up study. Epilepsia 1996;37:1155-63.

Sachdev P. Schizophrenia-like psychosis and epilepsy: the status of the association. $A m$ J Psychiatry 1998;155:325-36.

Schwartz JM, Marsh L. The psychiatric perspectives of epilepsy. Psychosomatics 2000;41:31-8.

Stevens JR. Clozapine: the Yin and Yang of seizures and psychosis. Biol Psychiatry 1995;37:425-6.

Mace CJ. Epilepsy and schizophrenia. Br J Psychiatry 1993;163:439-45.

Krishnamoorthy ES. Psychiatric issues in epilepsy. Curr Opin Neurol 2001;14:217-24.

Toone BK. The psychoses of epilepsy.J Neurol Neurosurg Psychiatry 2000;69:1-3.

Adachi N, Matsuura M, Okubo Y, Oana Y, Takei N, Kato M et al. Predictive variables of interictal psychosis in epilepsy. Neurology 2000;55:1310-4.

10 Slater E, Moran PA. The schizophrenia-like psychoses of epilepsy: relation between ages of onset. Br J Psychiatry 1969;115:599-600.

11 Malig C. The civil registration system in Denmark. Tech Pap Int Inst Vital Registr Stat 1996;66:1-6.

12 Andersen TF, Madsen M, Jorgensen J, Mellemkjoer L, Olsen JH. The Danish national hospital register. A valuable source of data for modern health sciences. Dan Med Bull 1999;46:263-8.

13 Munk-Jorgensen P, Mortensen PB. The Danish psychiatric central register. Dan Med Bull 1997;44:82-4

14 Zarrelli MM, Beghi E, Rocca WA, Hauser WA. Incidence of epileptic syndromes in Rochester, Minnesota: 1980-1984. Epilepsia 1999;40:1708-14.

15 McDonald C, Murphy KC. The new genetics of schizophrenia. Psychiatr Clin North Am 2003;26:41-63.

16 Huang J, Jiang Y. Genetic linkage analysis of a dichotomous trait incorporating a tightly linked quantitative trait in affected sib pairs. Am J Hum Genet 2003;72:949-60.

17 Cardno AG, Rijsdijk FV, Sham PC, Murray RM, McGuffin P. A twin study of genetic relationships between psychotic symptoms. Am J Psychiatry 2002;159:539-45.

18 Maier W, Lichtermann D, Minges J. Hallmayer J, Heun R, Benkert O, et al. Continuity and discontinuity of affective disorders and schizophrenia. Results of a controlled famand discontinuity of affective disorders and schizo
ily study. Arch Gen Psychiatry 1993;50:871-83.

19 Perez MM, Trimble MR, Murray NM, Reider I. Epileptic psychosis: an evaluation of PSE profiles. BrJ Psychiatry 1985;146:155-63. 
20 Sengoku A, Yagi K, Seino M, Wada T. Risks of occurrence of psychoses in relation to the types of epilepsies and epileptic seizures. Folia Psychiatr Neurol Jpn 1983;37:221-5.

21 Kristensen O, Sindrup EH. Psychomotor epilepsy and psychosis. I. Physical aspects. Acta Neurol Scand 1978;57:361-9.

22 Adachi N, Onuma T, Hara T, Matsuura M, Okubo Y, Kato M, et al. Frequency and agerelated variables in interictal psychoses in localization-related epilepsies. Epilepsy Res 2002;48:25-31.

23 Schmitz EB, Robertson MM, Trimble MR. Depression and schizophrenia in epilepsy: social and biological risk factors. Epilepsy Res 1999;35:59-68.

24 Mendez MF, Grau R, Doss RC, Taylor JL. Schizophrenia in epilepsy: seizure and psychosis variables. Neurology 1993;43:1073-7.

25 Stafstrom CE. Assessing the behavioral and cognitive effects of seizures on the developing brain. Prog Brain Res 2002;135:377-90.

(Accepted 29 April 2005)

doi $10.1136 /$ bmj.38488.462037.8F
National Centre for Register-based Research, University of Aarhus, Taasingegade 1, DK-8000, Aarhus C, Denmark

Ping Qin associate professor

Thomas Munk Laursen statistician

Preben Bo Mortensen professor

Department of Social Medicine and Health Management, School of Public Health, Central South University, China

Huilan $\mathrm{Xu}$ associate professor

Department of Epidemiology, Institute of Public Health, University of Aarhus, Denmark

Mogens Vestergaard assistant professor

Correspondence to: P Qin pq@ncrr.dk 